\title{
The Medical Home, Health Services, and Clinical Family Medicine Research
}

This September/October 2008 issue of the Fournal of the American Board of Family Medicine ( $7 A B F M$ ) features a multifaceted discussion on the medical home, plus a selection of health services research and clinical research with a broad base of funding, investigators, and spectrum of primary care settings. Here we highlight studies that provide new/ clarifying results, ${ }^{1-5}$ mixed results, ${ }^{6-8}$ and unexpected results. ${ }^{6,7}$ Several reports provide information and data on major tenets of family medicine: Clark et $\mathrm{al}^{6}$ studied continuity between prenatal care and infant care; Mainous et $\mathrm{al}^{5}$ described the long-term personal history importance to future risk of disease; and Merenstein and Merenstein ${ }^{9}$ provide patient feedback on the importance of the doctor-patient relationship.

\section{The Medical Home}

The drum-beat for the patient-centered medical home is getting louder. Herein we feature discussions and commentary about the medical home. ${ }^{10-13}$ In a commentary, Rogers ${ }^{10}$ summarizes the patient-centered medical home movement, considering in turn its strengths, weaknesses, opportunities, and threats, and finishes with a simple yet difficult and demanding action agenda. Rosenthal ${ }^{11}$ provides a literature review on the benefits of the medical home. Daaleman ${ }^{13}$ places the medical home in a philosophical context and offers a perspective about future medical homes as practical sites of formation for family physicians. In comprehending care in a medical home, DeVoe ${ }^{12}$ advocates that efforts to ensure universal access to a usual source of care must be partnered with broader awareness and training of providers to engage patients equally in making health care decisions at the point of care. Then, in a related special communication, Fink ${ }^{14}$ discusses deficiencies in the valuedriven health care model.

Conflict of interest: The authors are editors and staff of the FABFM.

\section{Reproductive Technology}

From an individual practice: Stanford et $\mathrm{al}^{1}$ present some really exciting information: using National Procreative Technology (often with additional support of clomiphene and/or other medications), one-quarter of couples who had been infertile for more than $5 \mathrm{yr}$ (with the women averaging $36 \mathrm{yr}$ of age) had babies within $2 \mathrm{yr}$ (by intention to treat analysis). This certainly presents an interesting possibility for patients seeking alternatives to in vitro fertilization, but the results should be verified in other settings as well.

\section{Health Services Delivery}

From a state Medicaid database: Clark et $\mathrm{al}^{6}$ found that continuity of site for mother in the prenatal period and the infant in the postnatal period (approximately one-half of the infants) was associated with additional well-child and emergency department (ED) visits but no reduction in hospitalizations. This study raises more questions that it answers-we usually hope that continuity, even from mother to infant, helps prevent $\mathrm{ED}$ visits. Is there something different about these families, their illnesses, or the office where this type of continuity occurs that could account for this? Did the increase in emergency visits and well-child visits result in other indicators of improved health? For example, were these children better immunized, or more likely to be checked for lead? We hope that the authors continue to pursue the implications for our practices.

In a multiethnic university-based family medicine office with high levels of insurance coverage: Shokar et $\mathrm{al}^{2}$ found that doctor recommendation and patient education about colorectal cancer screening were more important than personal beliefs, including fatalism, in whether or not patients were up to date with colon cancer screening. Increasing patient awareness, and finding ways to encourage physicians to recommend screening, remain important avenues to increase colorectal cancer screening. 
From a large National Institutes of Healthfunded study: Mainous et $\mathrm{al}^{5}$ looked at changes in risk factors for heart disease over time and the relationship to actual heart disease. The bottom line is that although lifestyle risk factors may change, with heart disease, it is not that easy to get rid of past risks. As the authors state, "this finding provides a potential explanation for the lack of additional value of many current state biomarkers with conventional risk factors and points to the need for a measure that assesses a cumulative risk." Continuity of care over time may help family physicians better estimate current pretest probability of heart disease given current symptoms than just considering apparent risk in noncontinuity care, particularly for women.

From patient farewell letters: In a unique piece, Merenstein and Merenstein ${ }^{9}$ read and completed content analysis on 200 spontaneous letters and notes from patients to their long-term retiring family physician, reinforcing the importance of many tenets of family medicine, such as caring, continuity, "being there," and care of the family.

\section{Anxiety and Depression Studies}

From 3 family practices in Boston: Fogarty et $\mathrm{al}^{4}$ report that mental health disorders, particularly those with significant anxiety (anxiety disorders, panic disorders, and posttraumatic stress disorders), were associated with increased use of medical care. This is consistent with the fact that patients with anxiety activate and push for resolution, whereas patients with depression do not.

From a large study of managed care patients: Rush et $\mathrm{al}^{7}$ found that diabetes patients with depression symptoms were less likely to achieve glucose goals, but this improved when they were treated with antidepressants. The achievement of lipid goals was not associated with depression or its treatment, although testing rates were lower in patients with depression symptoms.

\section{Clinical Medicine}

From our interesting brief reports, Willis et $\mathrm{al}^{3}$ present a case report in which treatment of sleep apnea led to resolution of recurrent syncope. Holve and Barkan ${ }^{8}$ present a small controlled trial of steroids for sciatica, a treatment that I (MAB) admit using occasionally based on "personal communication" with my older family physician mentors.

\section{Primary Care Research Funding Sources}

In addition to all this great data, our papers include information on the variety of sources of funding for family medicine research: federal funding from the National Institutes of Health, 2,3,5 the Agency for Health Research and Quality, ${ }^{7,12}$ and the Health Resources and Services Administration ${ }^{5}$; and foundation funding from the American Academy of Family Physicians Foundation, ${ }^{6}$ the Robert Wood Johnson Foundation, ${ }^{5}$ the John Sealy Memorial Endowment Fund for Biomedical Research, ${ }^{2}$ the Mayo Foundation for Medical Education and Research, ${ }^{3}$ and foundations associated with large HMOs. ${ }^{7,8}$ The American Academy of Family Physicians provided support, ${ }^{4,6}$ as did the Robert Graham Center for Policy Studies in Family Medicine and Primary Care, ${ }^{12}$ along with a commercial pharmaceutical company. ${ }^{4}$ And from those with the "fire in the belly": physicians, small practices, and university departments funding their own research. ${ }^{1,9,11,13-15}$ Thank you to all!

This issue epitomizes why we are always so impressed with the variety of funding sources, the level of collaborative work (across institutions and countries), and the number of individual family physicians in various practice settings that participate in research to advance the science of family medicine.

\section{Cover to Cover Feature}

To preserve the scholarly record and ensure that our readers can access the same information both in print and online, the $\mathcal{A} A B F M$ is proud to present the new cover-to-cover feature, which was unveiled for the special July/August 2008 practice-based research issue. This feature will display the cover, front matter, table of contents, and back matter (advertising will be excluded) that appears in each print issue from July/August 2008 forward. Readers can access this feature by going to the online table of contents for a particular issue and clicking on a link for the desired information; this action will return a PDF version of the print matter. The editors and editorial staff of the $\mathcal{F} A B F M$ hope readers will find this new feature useful and informative.

Marjorie A. Bowman, MD, MPA

Anne Victoria Neale, $\mathrm{PhD}, \mathrm{MPH}$

Phillip Lupo, MLIS 


\section{References}

1. Stanford JB, Parnell TA, Boyle PC. Outcomes from treatment of infertility with natural procreative technology in an Irish general practice. J Am Board Fam Med 2008;21(5):375-84.

2. Shokar NK, Carlson CA, Weller SC. Factors associated with racial/ethnic differences in colorectal cancer screening. J Am Board Fam Med 2008;21(5): 414-26.

3. Willis FB, Isley AL, Geda YE, Quarles L, Fredrickson PA. Resolution of syncope with treatment of sleep apnea. J Am Board Fam Med 2008;21(5): $466-8$.

4. Fogarty CT, Sharma S, Chetty VK, Culpepper L. Mental health conditions are associated with increased health care utilization among urban family medicine patients. J Am Board Fam Med 2008;21(5): 398-407.

5. Mainous AG, Everett CJ, Player MS, King DE, Diaz VA. Importance of a patient's personal health history on assessments of future risk of coronary heart disease. J Am Board Fam Med 2008;21(5):408-13.

6. Clark EC, Saultz J, Buckley DI, Rdesinski R, Goldberg B, Gill JM. The association of family continuity with infant health service use. J Am Board Fam Med 2008;21(5):385-91.

7. Rush WA, Whitebird RR, Rush MR, Solberg LI,
O'Connor PJ. Depression in patients with diabetes: does it impact clinical goals? J Am Board Fam Med 2008;21(5):392-7.

8. Holve RL, Barkan H. Oral steroids in initial treatment of acute sciatica. J Am Board Fam Med 2008; 21(5):469-74.

9. Merenstein B, Merenstein J. Patient reflections: saying good-bye to a retiring family doctor. J Am Board Fam Med 2008;21(5):461-5.

10. Rogers JC. The patient-centered medical home movement-promise and peril for family medicine. J Am Board Fam Med 2008;21(5):370-4.

11. Rosenthal TC. The medical home: growing evidence to support a new approach to primary care. J Am Board Fam Med 2008;21(5):427-40.

12. DeVoe JE, Wallace LS, Pandhi N, Solotaroff R, Fryer GE. Comprehending care in a medical home: a usual source of care and patient perceptions about healthcare communication. J Am Board Fam Med 2008;21(5):441-50.

13. Daaleman TP. The medical home: locus of physician formation. J Am Board Fam Med 2008;21(5):451-7.

14. Fink KS. Value-driven health care: proceed with caution. J Am Board Fam Med 2008;21(5):458-60.

15. Rohrer JE, Yapuncich KM, Adamson SC, Angstman $\mathrm{KB}$. Do retail clinics increase early return visits for pediatric patients? J Am Board Fam Med 2008;21(5): $475-6$. 